Gerión. Revista de Historia Antigua

ISSN: 0213-0181

https://dx.doi.org/10.5209/geri.74786

\title{
Adriano y Gades: una relación familiar ${ }^{1}$
}

\author{
Mª Pilar González-Conde Puente ${ }^{2}$
}

Recibido: 13 de enero de 2020 / Aceptado: 30 de septiembre de 2020

Resumen. El presente trabajo aborda la relación de Adriano con su familia materna y, a través de ella, con la propia ciudad de Gades (Cádiz, España), la ciudad de la que ésta procedía. La figura de L. Iulius Ursus Servianus, marido de su hermana, tuvo evidentemente un papel muy relevante en esta relación. A través del tratamiento en las fuentes clásicas se analiza la evolución de esta relación desde los momentos finales del gobierno de Nerva hasta la muerte de Servianus, para determinar hasta qué punto tuvo relevancia en algunas decisiones de Adriano.

Palabras clave: Adriano; Gades; Hispania; Baetica; Domitia Paulina; L. Iulius Ursus Servianus.

\section{[en] Hadrian and Gades: A Family Relationship}

Abstract. This work is about Hadrian's relationship with his maternal family and, through it, with the city of Gades (Cádiz, Spain), the city from which she came. The figure of L. Iulius Ursus Servianus, her sister's husband, obviously had a very important role in this relationship. Through the treatment in the classical sources, the evolution of this relationship is analyzed from the final moments of the Nerva's government until the death of Servianus, to determine to what extent it had relevance in some Hadrian's decisions.

Keywords: Hadrian, Gades; Hispania; Baetica; Domitia Paulina; L. Iulius Ursus Servianus.

Sumario. 1. El vínculo gaditano. 2. La entrada de L. Ursus Servianus en el círculo familiar gaditano. 3. Recapitulación. 4. Referencias bibliográficas.

Cómo citar: González-Conde Puente, $\mathrm{M}^{\mathrm{a}}$ P. (2021): Adriano y Gades: una relación familiar, en Gerión 39/1, 149-165.

\footnotetext{
1 Este trabajo se ha realizado en el marco del proyecto de investigación "Poblamiento de época romana y evolución del hábito epigráfico en Hispania citerior y norte de Lusitania" (PID2019-106169GB-I00), subvencionado por el Ministerio de Ciencia e Innovación del Gobierno de España. Agradezco a los revisores de este artículo sus indicaciones, que han ayudado a mejorarlo.

2 Universidad de Alicante.

E-mail: pilar.gonzalez@ua.es

ORCID: 0000-0002-9374-3932
} 


\section{El vínculo gaditano}

Cuando en el siglo III d.C. decía Dion Casio que el emperador Adriano no había visitado su patria, se refería sin duda a la ciudad de Italica, de la que procedía su familia paterna. ${ }^{3}$ Se asume de forma general, y sin duda así se debe interpretar, que el escritor severiano hablaba de la ciudad bética y no de Hispania, ${ }^{4}$ en donde Adriano estuvo en uno de sus desplazamientos durante sus años de gobierno y, más en concreto, en el invierno de los años 122-123 d.C. Nadie duda de que el escritor hablaba de la ciudad a la que siempre se vinculó al Príncipe, aunque casi con toda seguridad no había nacido en ella por una simple cuestión de funcionamiento administrativo, derivado del normal discurrir del cursus honorum de un senador como había sido Hadrianus Afer. Por supuesto, Dion Casio se refería a la patria paterna, aunque no lo estableciera claramente, porque la vinculación de Adriano con Gades, la ciudad de nacimiento de su madre, es prácticamente inexistente en las fuentes clásicas y una cuestión todavía a tratar en la bibliografía científica contemporánea. La falta de noticias impide un mayor desarrollo de la cuestión desde la perspectiva de la literatura latina.

La única referencia literaria al vínculo familiar adrianeo con Gades se produce a través de una noticia de la Historia Augusta, en la que el biógrafo del Príncipe afirma que Domitia Paulina, la madre imperial, había nacido alli. ${ }^{5}$ Previamente se había referido a Italica, la patria paterna, pero se ocupó el escritor de recordar

\footnotetext{
D.C. 69.10.1. Sobre el nacimiento y procedencia de Adriano: App. Ib. 38; Gell. 16.13 .4 (ortus, en referencia a su patria); D.C. 69.1 .1 (compatriota de Trajano) y 69.10.1 (sobre su patria); Hadr. 1.3 (nació en Roma); 2.2 (su patria hispana); y 19.1 (su país natal, a diferencia de Hadria, su segunda patria). Entre las fuentes tardías: Eutr. Brev. 8.6 (sobre el lugar de nacimiento); Aur. Vict. Caes. 13, 11 (... Hadriano civi propinquoque); Hieron. Chron. 224, 1 (sobre la base de Eusebio de Cesarea). Con una puesta en valor de la Apotelesmática de Hefestión de Tebas (Heph. Astr. Apot. 2.18), identificando uno de los horóscopos hechos por Antígono de Nicea con el de Adriano, vid. Caballos Rufino 1986, passim. También sobre esta cuestión de la procedencia familiar y del nacimiento de Adriano: Caballos Rufino 1984, 238; 2004, 35-55, con la demostración de que, en determinado momento (el autor dice que la responsabilidad de atribuirle un nacimiento bético fue de Dion Casio y luego de Eutropio), las fuentes confundieron ortus con natus (es decir, el lugar de procedencia con el lugar de nacimiento de Adriano), pero que nació en Roma, porque su padre debía estar allí como pretor. Esta opinión se acepta hoy de forma mayoritaria y ha sido defendida por Birley 2000, 10 (en contra, Canto de Gregorio 2004, 367-408).

4 Sobre el origen provincial de Trajano, Adriano y Marco Aurelio, la historiografía latina tiende a dar una explicación para poder aceptar socialmente la llegada a la jefatura del Estado de un senador de procedencia extraitálica. Para aquéllos que nacieron en Italia o cuyas familias procedían de allí, bastaba con decir que eran de familia ilustre y antigua. Esta diferencia se aprecia en diversos autores y épocas: la Historia Augusta dice que Adriano nació en Roma y que procedía de una familia afincada en Hispania, pero se ocupó de recordar que habían llegado desde Italia (Hist. Aug. Hadr. 1.1), mientras que para Marco Aurelio, al hacer su genealogía, sólo da el origen de su abuelo, M. Annius Verus, de quien dice que era de Sucuba -por Ucubi, actual Espejo, en la Bética- (Hist. Aug. Marc. Ant. 1.4); Dion Casio afirma que Nerva había preferido adoptar a un hispano antes que a un itálico, destacando la habilidad sobre el origen, mientras que de Adriano se limitó a decir que era un compatriota de Trajano y que nunca visitó su patria (en referencia a la ciudad de origen, Italica; D.C. 68.4.1-2 y 69.1.1 respectivamente); Eutropio dice que Trajano y Adriano nacieron en Italica, en Hispania, mientras que no aborda la cuestión del origen para Marco Aurelio (Eutr. Brev. 8.2.1; 8.6.2); Aurelio Víctor sólo afirma que Trajano era de Italica y no se refiere a la procedencia de Adriano, mientras que hace de Lanuvium a Antonino Pío y a Marco Aurelio (Aur. Vict. Caes. 13.1; 15.2; 16.1). Sirvan de ejemplo estas fuentes del tratamiento que se da a la cuestión en la historiografía greco-latina.

5 Hist. Aug. Hadr. 1.2: Gadibus orta (una expresión que se refiere al nacimiento y no necesariamente al origen). Una carta de Adriano en la que dice "madre" no tiene que referirse necesariamente a Domitia Paulina, porque el Príncipe también se dirigía así a Plotina y a Matidia: Corp. Gloss. Lat. 3, 37; PIR D 185: con esta opinión. Sobre el tratamiento de los Antoninos en la Historia Augusta: Chausson 2007, 155-163 (a propósito de la orientación dada deliberadamente en las biografías y los "silencios" que contienen).
} 
que, aunque provincianos, eran originarios de Italia, porque el propio Adriano decía que habían llegado desde Hadria. El funcionamiento de la sociedad romana, estrictamente patriarcal, concedía una importancia extrema a los vínculos familiares paternos. Los padres procuraban a sus hijos varones un nombre que identificara la continuidad familiar por vía paterna, como ocurrió con el propio Adriano, que compartía onomástica con su padre y que ha quedado históricamente vinculado a la ciudad de Italica. Otra cosa era la descendencia femenina, que con cierta frecuencia reflejaba una onomástica derivada de la materna, especialmente si la madre procedía de una familia de la élite. Por su parte, los matrimonios en los grupos privilegiados en Roma y las provincias se resolvían generalmente con la unión de cónyuges de dos familias aristocráticas. En el caso de Adriano, su padre procedía de la élite de Italica mientras su madre era, sin duda, una mujer de una destacada familia senatorial, pues de otra manera no hubiera sido aceptada fácilmente en el grupo italicense. Se trataba de una unión entre dos grupos de las élites vinculadas a la Bética ${ }^{6}$ aunque la rama materna quedó casi totalmente olvidada. ${ }^{7}$

La figura de Domitia Paulina maior fue ignorada sistemáticamente por los escritores greco-latinos. Su nombre, procedencia y relación materno-filial con Adriano $^{8}$ se ha conservado a través de la Historia Augusta y aún entonces se la mencionaba en un contexto de explicación familiar en el que no era la protagonista y en donde resultaba necesario hablar de ella porque se hacía la relación completa de los parientes cercanos. ${ }^{9}$ La Vita Hadriani comienza, como no podía ser de otra manera, con los datos familiares del Príncipe, entre los que figuraban los nombres de su padre, su madre, su hermana, su abuelo y su esposa, además del parentesco con Trajano. Es evidente que entre ellos no podía faltar su madre, Domitia Paulina, de quien el biógrafo recordó que había nacido en Gades, un dato que no aportó para el resto de los parientes. De todos ellos dio exclusivamente el nombre, aunque no evitó recordar que Domitia Paulina minor, la hermana de Adriano, estaba casada con Servianus, es decir, con L. Iulius Ursus Servianus. ${ }^{10}$

\footnotetext{
Sobre los vínculos maternos con Gades: Di Vita-Evrard 2000, 35-36, a propósito de que la madre de Adriano habría venido al mundo en Gades porque esta ciudad pudo ser la patria (o quizá mejor el lugar de asentamiento) de su familia materna (es decir, Curtilia, hija de T. Curtilius Mancia, debió estar en la ciudad de procedencia de su suegra, Dasumia, cuando dio a luz a Domitia Paulina Lucilla maior; la autora considera que esta Dasumia pudo ser Dasumia Polla). En todo caso, Dasumia sí tenía un origen bético (véase nota 9 con más bibliografía). Así ocurrió también, por ejemplo, con la madre de Trajano, de quien se desconoce todo y sólo se ha podido suponer que llevara el nomen Marcia o el cognomen Marciana, a juzgar por la onomástica de la hermana imperial, Ulpia Marciana. Sobre esta cuestión y sus posibles parentescos: Bennett 2001, 11-12; Mayer i Olivé 2018, passim (explicando el silencio sobre Domitia Paulina en las fuentes por una posible relación familiar con los Flavios, de manera que su mención hubiera sido inoportuna en una nueva época que empezaba tras la damnatio memoriae de Domiciano); Baratta 2019, 175.

8 Hist. Aug. Hadr. 1.2: Hadriano pater Aelius Hadrianus cognomento Afer fuit, consobrinus Traiani imperatoris; mater Domitia Paulina Gadibus orta, soror Paulina nupta Serviano, uxor Sabina, atavus Maryllinus, qui primus in sua familia senator populi Romani fuit. La edición utilizada es la de J.-P. Callu (Les Belles Lettres).

9 G. Di Vita-Evrard ha defendido la identificación de Domitia Paulina (así llamada en la Vita Hadriani), conocida como Domitia Paulina maior (a diferencia de su hija, Domitia Paulina minor), con Domitia Lucilla maior (o mejor Domitia Paulina Lucilla): Di Vita-Evrard 1987a, tab. 2c (con nuevo stemma); 1987b, 509-510; 1989, 164-169 y 173 (con la explicación sobre el verdadero testador y los beneficiarios del mismo en primer y segundo grado, así como el nuevo stemma); 2000, 36 (con la genealogía de Adriano a partir de la interpretación de la autora para CIL VI 10229, el llamado Testamentum Dasumii) y passim. Con esta misma interpretación y dotando de una secuencia cronológica a esta sucesión familiar: Chausson 2009a, 209-210 (en las conclusiones).

10 Sobre L. Iulius Ursus Servianus: PIR ${ }^{2}$ I 631; Étienne 1965, n 4: no duda de su origen en Italica; Syme 1969, 232;
} 
Resulta difícil pensar que esta noticia sobre la procedencia de Paulina, aunque aislada, fuera producto de un error, porque la ciudad de Gades era sobradamente conocida en Roma, tanto por su papel durante la presencia púnica como por la importancia de Cornelio Balbo y en general por la fuerza de sus élites. ${ }^{11}$ De las palabras de Estrabón se deduce que no había caído en el olvido el hecho de que la ciudad había sido un referente en el Mediterráneo. ${ }^{12}$ En el siglo II d.C., la imagen de Hispania en Roma tenía, en gran parte, un componente de fosilización, que hacía recordar con frecuencia el estereotipo de un recuerdo fijado en el tiempo, por lo que se tenía muy presente la historia pasada de Hispania en general y de algunas ciudades hispanas en particular. ${ }^{13}$ Cuando en los siglos posteriores se afirmaba que la madre de un Príncipe de Roma procedía de allí, probablemente se trataba de una noticia que había que tomar en serio.

A diferencia de Trajano, el alcance de la política dinástica de Adriano fue muy limitado en sus manifestaciones y afectó exclusivamente a la relación con los Ulpii. Durante un tiempo, adoptó la onomástica paterna (de su padre adoptivo), que después abandonó. En las monedas, Adriano figuró junto a Trajano de forma muy limitada al comienzo de su gobierno, pero no fue hasta el 128 d.C. cuando se le representó vinculado a sus padres adoptivos, Trajano y Plotina, recordando su relación paterno-filial cuando ambos ya habían muerto. ${ }^{14}$ En cambio, Adriano obvió a su familia biológica, a la que no dio ningún papel institucional ni presencia en la numismática. Este silencio se ve agravado aún más por la falta de testimonios seguros de cualquier representación de sus parientes más cercanos en los espacios públicos de las ciudades, si es que la hubo..$^{15}$ Los Ulpii habían subido al poder con Trajano. Los Aelii no tuvieron, en cambio, ningún papel público. Sin embargo, en ambos casos hubo una actitud de indiferencia casi total hacia las madres de los dos príncipes. En el caso de Trajano, ni siquiera se conoce el nombre ni la procedencia de su madre. ${ }^{16}$ Para Adriano, como se ha dicho, las noticias son muy escasas.

Esta falta de interés sobre Domitia Paulina maior impide conocer si hubo una relación intensa de Adriano con algunos miembros de su familia materna y, lo que resulta más relevante aquí, con la ciudad en la que su madre había nacido. No ha sido

Eck 1970, 150-156; Castillo García 1982a, n 66; Caballos Rufino 1990, nº I, 130 (con las fuentes epigráficas para el personaje y su carrera); Michelotto 1987, passim: un homo novus que accede al senado al final del gobierno de Nerón o comienzos del de Vespasiano, según las opiniones); Des Boscs-Plateaux 2005, 505-506, $\mathrm{n}^{\circ}$ 53. Plinio el Joven le calificaba de hombre excelente en la carta de agradecimiento a Trajano por la concesión del ius trium liberorum, una petición en la que había mediado Servianus y de quien Plinio decía que amaba al Príncipe (Plin. Ep. 10.2).

11 Como ya recordaba A. R. Birley 2000, 10-12, a propósito de la patria materna de Adriano.

12 Str. 3.5.3. El geógrafo recuerda que la ciudad contaba con un censo de quinientos caballeros, más que cualquier ciudad de Italia excepto Padua, pero también que era uno de los puertos mediterráneos de donde salían las naves más grandes y mejores; Cruz Andreotti 1994, 71.

13 Blázquez Martínez 1982, passim; González-Conde Puente 2018a, 21-23.

14 La línea femenina de la familia de Trajano, impuesta porque la propia naturaleza le negó parientes varones cercanos, en realidad era un homenaje a su familia paterna, la de los Ulpii. Para la asociación con Trajano en la numismática de los primeros años de Adriano: RIC II Trajan 23-28. Esta misma asociación, con Trajano y Plotina, con la leyenda DIVIS PARENTIBVS: RIC II 232a y 387 (datadas respectivamente en 134-138 d.C. y sin cronología); González-Conde Puente 2018b, 138. Sobre el posible parentesco entre Plotina, Trajano y Adriano: Chausson 2007, 126, y n. 9 con la bibliografía anterior.

15 Baratta 2019 (sobre una posible representación suya en un grupo estatuario de la ciudad de la Loggia dei Lanzi, en Florencia).

16 Véase nota 6. 
posible determinar la presencia del Príncipe en Gades durante los dos viajes conocidos que realizó a la península Ibérica. En el primero, siendo un adolescente, estuvo en la Bética y resulta extraño pensar que no se acercara a la ciudad de nacimiento de su madre durante su estancia en la provincia, pero no hay ningún dato que lo corrobore. ${ }^{17}$ Para el segundo viaje hispano, realizado ya como monarca, ni siquiera se puede afirmar con seguridad que pasara por la Bética y mucho menos que visitara Gades, si bien es cierto que un posible viaje de Adriano hacia el sur de Hispania llevaría consigo la necesaria salida por uno de los puertos del sur peninsular. ${ }^{18} \mathrm{En}$ cualquier caso, hay que aceptar que, desde la cabeza del Estado romano, hubo algún gesto de acercamiento a un símbolo identificativo de la ciudad de Gades como fue el Herakleion. Así se desprende de las acuñaciones monetales que llevaban como motivo de reverso al Hercules Gaditanus, como queda atestiguado por la leyenda que lo acompaña. ${ }^{19}$ Era ésta una novedad en la ceca de Roma, porque las anteriores monedas trajaneas relativas a Hercules no parecen haberse referido de ninguna manera al culto de Gades, ya que les faltaba el epíteto y no hay ningún indicio de que deban asociarse al culto ubicado en el Extremo Occidente. ${ }^{20}$ Esta presencia del templo en la iconografía monetal puede vincularse, muy probablemente, a la noticia de Ulpiano acerca de una transformación jurídica del régimen de la institución, a la que se permitió aceptar herencias. ${ }^{21}$ Sin duda esta medida tendría una importante repercusión en los años siguientes en las finanzas del santuario. Aunque no hay una absoluta seguridad sobre la datación de esta norma, se ha planteado la posibilidad de que se hiciera en los años de gobierno de Adriano. J. Mangas llamó la atención acerca de que los beneficios dados a los templos se plasmaron en la numismática en ese período con sus divinidades como motivos numismáticos. ${ }^{22}$

En consonancia con esta atención al Herakleion, en su recinto pudo haberse colocado una imagen de Adriano. En este sentido se puede quizá interpretar la escultura sin cabeza hallada en los alrededores de Sancti Petri (Cádiz) de un emperador divinizado, que presenta un grado de deterioro considerable debido a su permanencia bajo el agua y que se conserva actualmente en el Museo de Cádiz. Ya A. García y Bellido la dató en la primera mitad del siglo II d.C. y la investigación posterior la

\footnotetext{
Birley 2000, 23-25.
}

18 Sobre el itinerario hispano: Halfmann 1986, 196-197; Birley 2000, 146-150; Alfdöldy 2014, 15. Para un resumen sobre el estado de la cuestión: González-Conde 2019, 46-48.

19 RIC II Hadrian 125 (áureos de 119-122 d.C.). También se acuñaron monedas con la representación de Hercules, aunque sin el apelativo Gaditanus (RIC II Hadrian, 148-150), como ya se había hecho bajo Trajano (aunque éste último no tenía vinculación aparente con la Bética). Sobre el sentido de estas acuñaciones adrianeas: Moreno Pulido 2013, 37-39.

20 RIC II Trajan 37, 49-51, 112, 152, 689-690, 773 y 802 (ninguno de ellos como Hercules Gaditanus); Woytek 72a y 73a, 99a y 100a, 99c-e y 100c, 101a, 595a, 595b, 806, 837. En cambio, en el arco de Benevento se representó a Trajano ante Hercules, que está acompañado por un perro, un olivo y un caballo, lo que se ha considerado una representación de Hispania. Sobre esta escena y una posible identificación con la divinidad en su versión gaditana: Strack 1931, vol. I, 95-105; Beaujeu 1955, 431-437; Bennett 2001, 72 y n. 82, considera que hay elementos en la iconografía trajanea para considerar que Hercules Gaditanus está presente en Roma en ese período.

21 Ulp. 22.6. En relación con esto: Perea Yébenes 2001, 142-143, quien conecta el texto de Ulpiano con el kalendarium Gaditanorum de Fr. Vaticana 187 (en el contexto de medidas de Ulpiano), que dejaba exento de la tutela al responsable de este kalendarium, que era un ecuestre. Sobre las condiciones económicas del templo a través del tiempo: Rodríguez Ferrer 1988, passim.

22 Se discute si la medida corresponde a Trajano o Adriano: Mangas Manjarrés 1989, 57. Sobre la pérdida de importancia del templo en época altoimperial ya habló Étienne 1974, 522. 
ha vinculado a este contexto adrianeo y al templo de Hercules Gaditanus. ${ }^{23}$ Sería deseable completar estos datos con el conocimiento de alguno de los sacerdotes dedicados al culto al Hercules de Gades, pero no se conserva la identidad de ninguno de ellos. En el período precedente, posiblemente bajo Trajano, se ha vinculado este culto a un sacerdote de Hercules procedente de Carteia, en cuya inscripción no figura el epíteto Gaditanus pero se ha considerado esta posibilidad por la cercanía geográfica. ${ }^{24}$ Se trata de $Q$. Cornelius Senecio Annianus, que habría iniciado así una carrera, si se acepta esta vinculación con el dios gaditano, que después le llevaría a la asamblea del Senado. ${ }^{25}$

En cualquier caso, no se puede afirmar que Adriano desatendiera totalmente su vinculación con Gades, habida cuenta de la presencia en las monedas. Sin embargo, las fuentes literarias posteriores conservadas hasta hoy olvidaron casi por completo la importancia de Gades como lugar de procedencia o de asentamiento familiar de Adriano y la posible atención imperial, si la hubo, hacia la ciudad bética. ${ }^{26}$ No se menciona una potencial estancia en ella ni ninguna de las mejoras urbanísticas a las que tan aficionado fue el Príncipe. El argumento ex silentio de los escritores antiguos cuya obra se ha conservado no puede ser esgrimido, como es obvio, para negar una cercanía del Príncipe con la ciudad de procedencia materna, pero sí para demostrar que la construcción de la imagen política de Adriano como cabeza del Estado romano no se proyectó utilizando su vinculación familiar con Gades, como sí se hizo en cambio con otros lazos familiares.

Adriano se quedó huérfano de padre siendo todavía un niño. Es sobradamente conocido que creció en el entorno de Trajano, quien había sido nombrado su tutor

23 García y Bellido 1949, $\mathrm{n}^{\circ}$ 193: sin identificarla pero fechada en la primera mitad del siglo II d.C.; Garriguet Mata 2001, $\mathrm{n}^{\circ} 32$ : con la identificación y la relación con el templo ( $\mathrm{y} \mathrm{n}^{\circ} 31$ para la estatua de bronce con coraza); Ojeda Nogales 2011, n 11. Museo Arqueológico de Cádiz, $\mathrm{n}^{\circ}$ inv. 4583. Más imprecisa resulta la identificación de una escultura thoracata en bronce. Recientemente, para el emplazamiento del templo: Monterroso Checa 2021, 157-161.

24 De Carteia proceden varias noticias que, de una u otra manera, ponen en relación a la ciudad con el nombre o con el culto de Hercules: una estampilla sobre tegula con el nombre de Hercules (CIL II $1927=$ CIL II 6252f), aunque se ha interpretado como una marca de producción (Rico 1999, 34 y n. 16); una figura de bronce representando a este dios (Rogríguez Oliva 2011, 129-130 y n. 101 con las noticias anteriores); entre las monedas de la ceca de Carteia está la cabeza de Hercules como motivo de anverso, con una representación como divinidad romana (Chaves Tristán 2000, n 2260-2261); Estrabón señala que Timóstenes decía que existía la creencia de que Herakles había fundado Carteia y que ésta había llevado el nombre de Herakleia (Str. 3.1.7). Sobre esta cuestión, vid. entre otros: Padilla Monge 2011, 249-50.

25 CIL II 1929; González Fernández 1982, nº 85. En referencia al cargo sacerdotal, el texto conservado del epígrafe, hoy desaparecido, sólo dice sacerdoti Herculis, aunque la cercanía geográfica al templo invita a pensar que pudiera ser el culto gaditano. Sobre el personaje: PIR ${ }^{2}$ C 1450; Étienne 1965, nº 20; Alföldy 1969, 119; 1977, 201, 266, 286, 294, 300, 316 y 340; Castillo García 1982a, nº 41; Thomasson 1984, col. 248, nº 36 (gobierno de Bitinia); Eck 1996a, 216-217 y 219; Des Boscs-Plaetaux 2005, nº 125. Sobre los parecidos onomásticos, Caballos Rufino 1990, no 56: podría ser descendiente de Cornelius Senecio, el amigo de Séneca de cuya muerte hablaba en una carta a Lucilio (Sen. Ep. 101.1: sobre su muerte repentina); también pudo estar emparentado con dos personajes de cronología más tardía: L. Sterninius Quintilianus Acilius Strabo Q. Cornelius Rusticus Apronius Senecio Proculus (el cónsul del 146 d.C.) y con su hijo Q. Cornelius Senecio Proculus. Sobre un posible parentesco con los Annii de Acci conocidos a través de una inscripción de Graena (Granada): Delgado Delgado 1993, 360 (se da la circunstancia de que en esta familia hay varios sacerdocios a divinidades romanas, incluido Hercules); Padilla Monge 2011, 245-246. Acerca del carácter romano de este culto: Oria Segura 1989, 269; 1993, 178.

26 La propuesta de G. Di Vita-Evrard confirma un posible origen gaditano para Domitia Paulina maior (o Domitia Paulina Lucilla maior, según la autora), a través de quien habría sido su abuela materna (Dasumia, quizá Dasumia Polla, según la autora). Véase nota 6. 
junto a Acilius Attianus. ${ }^{27}$ El joven descendiente varón de un senador fallecido era inmediatamente protegido, cuando no adoptado, por parientes cercanos o por otros miembros de la élite que tuvieran contacto previo con la familia. Esa era la forma de asegurar la proyección pública posterior del vástago huérfano, que sería apoyado por otros colegas de su padre, incluso aunque la madre siguiera viva, porque se daba por supuesto que su condición femenina limitaba sus posibilidades de dar apoyo político a su hijo. En el caso de Adriano, esta circunstancia se produjo de la misma forma, tal y como reflejan las fuentes. Sin embargo, esto no quiere decir que Trajano y Attianus asumieran la tutela de los hijos de Hadrianus Afer y Domitia Paulina maior. La hija, Paulina minor, pudo quedar exclusivamente bajo la tutela de su madre tras el fallecimiento del padre, que se ocuparía de ella como había hecho hasta entonces. ${ }^{28}$

\section{La entrada de L. Ursus Servianus en el círculo familiar gaditano}

Cuando llegó el momento de casar a Paulina minor, se buscó un candidato con la suficiente relevancia. El elegido fue L. Iulius Ursus Servianus, que previamente había sido adoptado por L. Iulius Ursus. ${ }^{29}$ La mayor parte de la información que vincula a Adriano con su familia materna proviene del matrimonio de su propia hermana. Si las noticias sobre Domitia Paulina maior fueron casi inexistentes, las relativas a Domitia Paulina minor fueron escasas en cuanto a su relación con el Príncipe, pero mucho más abundantes en las referencias a su marido, dada la relevancia social y política de éste. Iulius Ursus Servianus se convirtió en cuñado de Adriano cuando éste era todavía muy joven. ${ }^{30}$ De cualquier manera, Servianus no pertenecía a la generación de Adriano o de su hermana, aunque eso no era relevante en una boda de carácter político como las que se celebraban entre los miembros del orden senatorial. Era un hombre con una carrera pública ya considerablemente desarrollada, que en el año 90 d.C. alcanzó el consulado y en el 102 d.C. lo obtuvo por segunda vez, quizá como consecuencia de su vinculación con la familia imperial. ${ }^{31}$ Durante el gobierno de Trajano, su situación junto al poder parece inmejorable, si recordamos la correspondencia de Plinio con Trajano, de la que se desprende que Servianus pidió para el escritor la concesión del ius trium liberorum y Trajano respondía afirmativamente, recordando además la excelencia del propio Servianus. ${ }^{32}$ Los motivos que llevaron a su elección como marido de Paulina minor eran claramente políticos, pero, lo que en aquellos momentos se vio como una alianza ventajosa para ambas partes, parece haberse convertido con el tiempo en un frente contra Adriano.

27 Hist. Aug. Hadr. 1.4 (sus tutores fueron Trajano y Caelius Attianus, una forma errónea de nombrar a Acilius Attianus) y 4.2; PIR A 45; Caballos Rufino 1990, $\mathrm{n}^{\circ} 5$ (con el resto de la bibliografía).

28 Quizá el nombre completo era Aelia Domitia Paulina: PIR ${ }^{2}$ D 186 (acepta que pueda llevar el nomen Aelia pero la ordena como Domitia, que es el único nomen seguro); Raepsaet-Charlier 1987, 35-37, $\mathrm{n}^{\circ}$ 12; Navarro Caballero 2017, 447, n 125 .

29 Véase nota 9 con la bibliografía. También para su posible parentesco con Adriano: Chausson 2013, 169, fig. 2 (con stemma) y passim.

30 Hist. Aug. Hadr. 2.6: a Serviano, sororis viro; Birley 2000, 10 (Domitia Paulina minor era sin duda mayor que Adriano) y 19 (probablemente estaban ya casados en el año 90, cuando Servianus alcanza su primer consulado, a juzgar por la biografía de la hija del matrimonio).

$31 \quad P I R^{2} \mathrm{I} 631$.

32 Véase nota 8. 
Si hacemos caso a la tradición literaria de corte senatorial, la enemistad entre Servianus y Adriano habría comenzado al menos a la muerte de Nerva, cuando el primero trató de impedir que Trajano se enterara por boca de Adriano de la noticia del fallecimiento de su predecesor. La anécdota parece poco creíble, tanto en el detalle de que Servianus se ocupara de estropear el carro de Adriano como en la idea de que éste pudiera viajar a pie, como si no tuviera otra opción, y aún así llegar antes que nadie a la presencia del inminente nuevo monarca. ${ }^{33} \mathrm{~A}$. Birley ya advirtió de que podría ser una construcción posterior del relato, transmitido a partir del enfriamiento de las relaciones entre ambos cuñados. ${ }^{34}$ Probablemente, lo más relevante de este relato no es la anécdota en sí misma, sino el hecho de que haya pasado a la historiografía posterior con tanta insistencia la enemistad entre Servianus y Adriano, especialmente en una fuente como la Vita Hadriani, que no le era particularmente hostil. Aunque no tengamos seguridad de cuándo comenzó este deterioro de la relación, lo cierto es que hay una intención de destacarla en las fuentes, seguramente por el final trágico de la misma.

Cuando Dion Casio contaba el viaje de Adriano a Egipto, durante el año 130 d.C., se permitió hacer una versión crítica de la actitud imperial tras la muerte de Antinoo. ${ }^{35}$ Sin duda un senador como el escritor severiano, a quien claramente no gustaba Adriano, no veía con buenos ojos el exagerado homenaje póstumo del Príncipe a su joven amante. ${ }^{36}$ Por esa causa, aprovechó para reprochar a Adriano que, tras la muerte, había tratado mejor a Antinoo que a su propia hermana, a la que no dedicó inmediatamente ningún honor. ${ }^{37}$ De las palabras de Dion Casio no puede deducirse la fecha de la muerte de Domitia Paulina minor, pero parece probable que se produjera mientras el Príncipe viajaba por Egipto, en el año 130 d.C., poco antes del trágico final del joven bitinio. Al

33 Hist. Aug. Hadr. 2.6: ex qua festinans ad Traianum, ut primus nuntiaret excessum Nervae, a Serviano, sororis viro, (qui et sumptibus et aere alieno eius prodito Traiani odium in eum movit) diu detentus fractoque consulte vehiculo tardatus, pedibus iter faciens eiusdem Serviani beneficiarium antevenit.

34 Birley 2000, 38. Las palabras de la Historia Augusta relativas a este episodio incluían también la crítica de Servianus por el gasto desmesurado y el endeudamiento del joven Adriano. Pero no era ésta la única referencia que su biógrafo hizo a un posible carácter irresponsable de Adriano en sus años de juventud. Basta recordar la frase sobre una excesiva afición a la caza que le valió una reprobación y, supuestamente, la salida de la Bética durante su adolescencia (Hist. Aug. Hadr. 2.1-2).

35 Para el viaje de Adriano a Egipto, entre la amplia bibliografía: Foullet 1968, passim (intentando demostrar que existió un segundo viaje en 134 d.C., que no se acepta en la actualidad); Birley 2000, 235-258 (con el único viaje al Nilo, cuyo inicio sitúa en julio-agosto de 130 d.C.); 2004, 69; Pfeiffer 2010, 152-165. La construcción de la via Hadriana nova entre Antinoopolis y el Mar Rojo demuestra que, aunque Adriano no visitara Egipto con posterioridad, continuó la atención al territorio: IGRR I, 1142; Pfeiffer 2015, 299, $\mathrm{n}^{\circ} 67$ (inscripción griega sobre la vía, datada a partir del año 136 d.C. por la mención a la segunda aclamación imperatoria y con más precisión en el 137 d.C. por ser el año décimo primero del gobierno de Adriano). Para precisar esta datación de Imperator II: Kienast - Eck - Heil 2017, 123: comienzos de 136 d.C. Sobre la visita de Vibia Sabina y Iulia Balbilla a los colosos de Memnon en noviembre del año 130 d.C., coincidiendo con la estancia imperial en la provincia: Bernard - Bernard 1960, nº 29-32.

36 Hay que recordar que, en el comienzo del libro 69, el relato sobre la llegada al poder de Adriano era despectivo hacia el nuevo Príncipe, de quien recordaba que no había sido adoptado realmente por su predecesor y que sólo era un compatriota (D.C. 69.1.1).

37 D.C. 69.11.4; Caballos Rufino 1990, n I 30: considera que la falta de homenaje fúnebre a Paulina, que contaba Dion Casio, era para no reforzar a Servianus, su marido. Aunque no hubo grandes honores a Paulina, Dion Casio no decía toda la verdad en este punto, puesto que el festival de juegos Adrianeos que llevaba el epíteto philadelfios se interpreta, por su propia denominación, como un homenaje a su hermana, a lo que hay que añadir el nombre dado a una tribu de Antinoopolis (aunque en un conjunto de nombres donde aparecía la familia y probablemente por su muerte reciente), como recordaba Birley 2000, 248-249, 254 y 257. 
menos en esa fecha ya debía haber una relación fría, o quizá abiertamente hostil, entre el Príncipe y el matrimonio de Paulina y Servianus. ${ }^{38}$

En el año 134 d.C., Iulius Ursus Servianus alcanzó el tercer consulado. Este detalle ha podido hacer pensar que la relación con Adriano debía ser buena, habida cuenta de que el monarca sólo tenía tres consulados también, lo que colocaba a ambos en una situación de igualdad en el Senado. La explicación de su biógrafo fue que el Príncipe no quiso ser su colega para no hablar en segundo lugar. ${ }^{39}$ Sin embargo, Adriano ya había desempeñado tres veces el consulado y precisamente la limitación de esta magistratura por el Príncipe era el producto de una manera de presentarse ante el Senado, como uno más de entre sus miembros y con una imagen de modestia, por lo que no parece que la decisión tuviera que ver con el nombramiento de su cuñado. En realidad, era la Asamblea la encargada de conceder el consulado, aunque los escritores posteriores no disimulaban a la hora de atribuir a la voluntad de los príncipes este honor, una circunstancia que debía responder ya a una realidad evidente. Por otra parte, hay que considerar que Adriano llevaba casi seis años fuera de Roma cuando su cuñado se convirtió en cónsul por tercera vez, ${ }^{40}$ lo que habría dificultado la realización de las funciones propias del cargo.

La obtención del tercer consulado por parte de algunos senadores no fue un honor muy extendido en tiempos de Adriano y el propio Príncipe había aceptado el cargo sólo en tres ocasiones. Es conocido que, además de Servianus, esta condición la tuvo también M. Annius Verus, el abuelo del futuro emperador Marco Aurelio, quien fue elegido para este puesto por tercera vez en el año 126 d.C., varios años antes de que lo consiguiera Servianus. ${ }^{41}$ La evolución de los consulados de ambos

38 Birley 2000, 247: deduce de las palabras de Dion Casio que Domitia Paulina minor había muerto ya, quizá en Alejandría. Sin embargo, no hay por qué suponer que acompañara a Adriano en su viaje a Egipto. Es posible que permaneciera en Roma junto a su marido, Servianus, que era ya octogenario, especialmente si la relación con su hermano no era demasiado cercana.

39 Hist. Aug. Hadr. 8.11; Birley 2000, 280 (Serviano alcanzó el tercer consulado, como cónsul ordinario, a comienzos del año 134 d.C. y lo desempeñó hasta el mes de abril, por lo que no debió recibir a Adriano a su llegada); 2004, 69 (la vuelta de Adriano a Roma se produjo el 5 de mayo de 134 d.C.). Más bien hay que pensar en otras razones para que Adriano no quisiera compartir el consulado (que para él sería el cuarto) con su cuñado Servianus: por una parte, la línea política de Adriano, que quiso distinguir a la Asamblea con un gesto al no aceptar el consulado más que en tres ocasiones; por otro lado, el Príncipe llevaba seis años fuera de Roma, lo que hubiera convertido el desempeño del cargo en un atrevimiento aún mayor.

40 Birley 2000, 280: probablemente Servianus ya no era cónsul cuando regresó el Príncipe y no tuvo que recibirle en virtud de su cargo.

41 No se aborda aquí una supuesta relación de los Annii Veri con la ciudad de Gades, que no parece haber existido o para la que, al menos, no hay ninguna evidencia. Desde el año 1965 (Étienne 1965, n. ${ }^{\text {o }}$ 17) se ha defendido que el abuelo de Marco Aurelio, M. Annius Verus (el cónsul del año 128 d.C.), se habría trasladado desde su patria (Ucubi) a Gades y allí habrían nacido sus hijos (sobre la base de PIR² A 667: M. Annius Libo). Desde entonces, una buena parte de la historiografía se ha basado en esta teoría. Sin embargo, como ya advirtió E. W. Haley (2003, 136 y n. 8 y 10), E. Groag nunca dijo eso a propósito de Libo ni de sus hermanos (entre ellos $M$. Annius Verus, el padre de Marco Aurelio). Por ello, no hacemos en este trabajo ninguna referencia a los Annii Veri como integrantes de la élite gaditana, a la que sí pertenecía Domitia Paulina maior. Tampoco Birley 2001, 243-245, hizo ninguna referencia a este traslado de los Annii Veri ni al nacimiento de la generación anterior a Marco Aurelio en Gades. Por lo tanto, no podemos establecer aquí ningún vínculo con la origo de Domitia Paulina maior. Sobre las posibles dudas acerca de la tribu a la que fueron adscritos los habitantes de Ucubi, es sabido que la familia de Marco Aurelio pertenecía a la Galeria. Según ha establecido A. U. Stylow (en $C I L \mathrm{II}^{2} / 5$, p. 118: praefatio de Ucubi), esta misma fue la tribu de los ucubitanos. Una inscripción hallada en Urso (CIL II $1404=C I L \mathrm{II}^{2} / 5,1025$ ) hace referencia a un duunviro de la colonia Claritas Iulia Ucubi que pertenecía a la tribu Sergia, pero la condición anterior del individuo, como centurión de la legio XXX, hace pensar que se había 
senadores parece bastante significativa. M. Annius Verus fue cónsul en los años 97 , 121 y 126 d.C.; Iulius Ursus Servianus lo fue en los años 90, 102 y 134 d.C. De estas fechas se deriva que los dos primeros consulados de cada uno parecen haber discurrido de una manera acorde con su edad y la evolución de sus carreras. En cambio, en el desempeño del tercer consulado hay ocho años de diferencia. Este honor tan infrecuente, que colocaba a un senador al mismo nivel que el Príncipe, fue concedido mucho tiempo antes a Annius Verus, mientras que, para Servianus, habían pasado ya treinta y dos años desde que lo ocupó por segunda vez. Con más de ochenta años y tras un lapso de tiempo tan prolongado, seguramente nadie esperaría ya que el cuñado del monarca tuviera ningún otro honor, más allá de los gestos de deferencia que quisiera concederle el monarca en la vida cotidiana por tratarse del marido de su hermana. ${ }^{42}$ En cualquier caso, el ascenso de Servianus a un tercer consulado, aunque tardío, no dejaba de ser un gran reconocimiento por lo infrecuente de su concesión, pero también hay que recordar que la Historia Augusta decía que Adriano concedió a muchos este tercer consulado: tertio consules, cum ipse ter fuisset, plurimos fecit, infinitos autem secundi consulatus honore cumulavit. ${ }^{43}$

Parece razonable pensar que la concesión del tercer consulado a Annius Verus suponía un refuerzo político de este senador y de su familia, mientras que, en el caso del tardío reconocimiento de Servianus, parece tratarse más de un honor dado cuando ya no podía haber consecuencias políticas en el gesto, por lo avanzado de su edad. Es cierto, sin embargo, que el tiempo se encargó de demostrar que el tercer consulado tuvo consecuencias en ambos casos: para Annius Verus pudo ser un impulso para que un miembro de su familia acabara con el tiempo asumiendo el poder en Roma; ${ }^{44}$ para Servianus desembocó en la pérdida de su vida y de sus esperanzas de sucesión para uno de sus descendientes.

El biógrafo de la Vita Hadriani decía que Adriano trataba con tanta consideración a Servianus que salía a recibirle cuando se encontraba en su dormitorio. ${ }^{45}$ Lo contaba en el mismo fragmento en el que hablaba de sus tres consulados. Sin embargo, este asunto no estaba limitado a ese momento, sino que correspondía, al parecer, a una práctica continuada. Por lo tanto, resulta imposible saber a qué época correspondía esa actitud y si se mantuvo de forma permanente a lo largo de la dilatada relación entre ambos. Podía ser una costumbre vinculada a los años de juventud de Adriano, cuando la cercanía de Servianus a Trajano hacía necesario que el joven Adriano se portara correctamente con él. En cualquier caso, se trataba del marido de su hermana, por lo que seguramente se mantendrían las formas en el seno de la familia hasta que la hostilidad estallara abiertamente.

instalado en la ciudad, en la que llegó a alcanzar la magistratura (Caballos 1978, 282-283: apunta otra visión, aunque advierte de que es una cuestión insegura).

42 Como ya advirtió Birley 2000, 280.

43 Hist. Aug. Hadr. 8.4: la expresión plurimos fecit requiere una reflexión que a menudo se olvida. Es evidente que el escritor debía referirse a senadores que hubieran desempeñado un tercer consulado como suffecti, ya que los cónsules ordinarios que lo ocupaban por tercera vez fueron M. Annius Verus y Iulius Ursus Servianus, además del propio Príncipe.

44 Chausson 2009b, 223 (stemma con los lazos entre los Annii y la familia de Adriano), 224-225 (con sus espectativas de alcanzar el poder) y passim. Previamente, el autor había tratado ya la cuestión de la familia de Marco Aurelio: Chausson 2002, passim.

45 Hist. Aug. Hadr. 8.11: Serviano sororis viro, cui tantum detulit ut ei venienti de cubiculo semper occurrerit (...). 
En el año 136 d.C. se produjo un acontecimiento sobradamente conocido y que dejó un impacto considerable en las élites romanas, como demuestra el hecho de que la historiografía posterior le dedicó bastante atención. Dion Casio, al hablar del período de gobierno de Adriano, se refirió tres veces a la muerte de Servianus y de su nieto, Pedanius Fuscus Salinator, lo que permite apreciar la importancia de este asunto entre las noticias que sin duda transmitieron los sectores más abiertamente antiadrianeos a partir de la muerte del Príncipe. ${ }^{46}$ Decía el escritor severiano que Adriano había pensado en Servianus incluso como alguien capaz para ocupar el Principado. Estas palabras acerca de la opinión de Adriano parecen en realidad una ficticia elaboración posterior o, como mínimo, una frivolidad expresada por el Príncipe sobre alguien que, por edad, no podía sucederle. Sobre este punto decía la Historia Augusta que Adriano apreciaba tanto a Servianus, que incluso pensó en él en los últimos momentos como un posible candidato..$^{47}$ Esta supuesta relación extrema, con episodios de devoción y admiración seguidos de un odio feroz, es sin duda una reconstrucción posterior que no respondería a la realidad, porque es impensable que Roma estuviera planeando en ningún momento que un senador cercano a los noventa años fuera el virtual heredero del Imperio. La misma biografía imperial contiene una contradicción al afirmar primero que Adriano y Servianus se odiaban ya cuando murió Nerva, para decir después que alguna vez Adriano le había considerado digno de la más alta magistratura.

Sin embargo, la Vita Hadriani no vinculó la muerte forzada de Servianus con la de su nieto Pedanius Fuscus Salinator. Sobre este barcinonense decía el escritor que Fuscus (sin duda se refería al yerno de Servianus) deseaba el poder y que Adriano le despreciaba. ${ }^{48}$ ¿Había tratado tanto Adriano a su sobrino político como para que éste despertara su desprecio? Cabe la posibilidad, como apuntó A. Birley, de que, durante su viaje a Hispania, Adriano se detuviera en Barcino, la patria de la gens Pedania, y de que incluso el Príncipe viajara entonces con su sobrina Iulia Paulina y el marido de ésta, Cn. Pedanius Fuscus Salinator. En todo caso, el Príncipe pudo también tratarle en Roma. Por entonces, el Fuscus nieto de Servianus sería sólo un niño muy pequeño, habida cuenta de que tenía dieciocho años cuando murió. En caso de que Adriano hubiera pensado alguna vez en esa familia para la sucesión, se habría fijado en Pedanius Fuscus Salinator, el yerno de Servianus, que pertenecía a la generación que ofrecía alguna posibilidad para la sucesión, aunque su muerte, anterior a la del propio Adriano, traspasaba el relevo al más joven Fuscus, bajo la protección de su abuelo. ${ }^{49}$

En todo caso, la notoriedad de M. Annius Verus debió poner en dificultades a cualquier descendiente de la gens Pedania. El senador, tres veces cónsul, parece haber formado parte de una voluntad imperial de destacar a la familia, que terminaría, unos años después y tras diversos avatares sobradamente conocidos, poniendo a uno de sus descendientes a la cabeza del Imperio. El adelanto de M. Annius Verus

46 D.C. $69.2 .6 ; 17.1-3 ; 23.2$ (esta última referencia, de forma genérica, alude a las muertes al comienzo y al final de su gobierno). Sobre los años finales de Adriano y los acontecimientos en torno a Servianus a través de Dion Casio: Migliorati 2003, 341-346.

47 Hist. Aug. Hadr. 23.2.

48 Hist. Aug. Hadr. 23.3: sin duda ese Fuscus era el marido de Iulia Paulina, la sobrina de Adriano, porque su hijo, el nieto de Servianus y homónimo de su padre, era sólo un niño que no podía tener ambiciones políticas. En contra, PIR P 198: que lo identifica con el joven nieto de Servianus.

$49 \quad P I R^{2}$ P 200. 
en la carrera política, frente a la ralentizada marcha de Servianus hacia el tercer consulado, demuestra que Adriano no tenía en el mejor concepto a su cuñado y que las noticias sobre la desconfianza y el odio mutuo tendrían sin duda algo de cierto. Sin embargo, también hay que recordar que el Príncipe estaba ya enfermo desde al menos el año 136 d.C. y que sin duda muchas de las decisiones, aunque fueran personales, vendrían mediatizadas por su entorno más cercano.

\section{Recapitulación}

En este punto, y a modo de recapitulación, conviene volver a la cuestión de la relación de Adriano con su familia materna, de la que Servianus formaba parte por matrimonio..$^{50}$ De todo lo dicho anteriormente se deduce que la relación de Adriano con esta rama familiar fue, como mínimo, distante. La proyección de una política dinástica se hizo exclusivamente a través de los Ulpii, con un alcance limitado, cuando fue necesario para justificar su ascenso al poder. Después de esto, Adriano ya sólo recurrió a esa imagen dinástica para dar impulso a sus candidatos a sucederle (aunque quizá entonces es el propio entorno imperial el que está actuando junto a un Príncipe envejecido y enfermo). Los Aelii no tuvieron papel institucional ni parece que tuvieran relevancia por su situación familiar junto al poder. Es posible que la muerte del padre alejara en cierto modo a Adriano de su familia materna, porque es conocido que pasó a estar tutelado por Trajano y Attianus, mientras muy probablemente su hermana quedara bajo la tutela de su propia madre. A esto se debe añadir un factor necesariamente relevante, como es el de la figura de Servianus. La hostilidad de Adriano hacia su cuñado marcó sin duda la relación con este entorno familiar gaditano pero afincado en Roma. Sólo así se entiende que el Príncipe ralentizara la culminación de la carrera de éste con un tercer consulado que se había concedido ya muchos años antes a un hispano, M. Annius Verus. No hay que olvidar que los matrimonios entre miembros del orden senatorial se arreglaban como pactos políticos y que no eran raros los divorcios, pero Paulina minor y Servianus no se separaron nunca y, por lo tanto, este senador estuvo siempre vinculado a los Domitii gaditanos. $^{51}$

Cuando se produce el viaje imperial a Hispania, Adriano no tendría muchos motivos para querer visitar la ciudad de Gades, al menos no había un fuerte vínculo personal que le hiciera acercarse a la ciudad. Se trataba de una ciudad vinculada a su familia materna y esta circunstancia se suele recordar cuando se quiere reconstruir el itinerario de la visita de Adriano, pero la realidad es que este argumento no debió pesar en sus decisiones. Otra cosa es que la necesidad de salir por algún lugar de la costa meridional peninsular le llevara hasta allí. En cualquier caso, independientemente de su presencia o ausencia en Gades durante esta estancia hispana, es inevitable

50 Desde el punto de vista jurídico, Servianus no formaba parte de la familia Aelia, sino que era Domitia Paulina minor quien entraba, por matrimonio, a formar parte de la de su marido. Sin embargo, el enlace establecía un parentesco con el Príncipe que hacía inevitable una relación familiar.

51 Ya se ha señalado que la vinculación materna con Gades se mantiene a pesar de los cambios que la investigación ha venido introduciendo. Véanse notas 6 y 9. Gades era el lugar de nacimiento de Domitia Paulina maior y, siguiendo a Di Vita-Evrard, podría ser también el lugar en el que estuviera asentada al menos una rama familiar de Dasumia Polla (probable abuela de la madre de Adriano). 
recordar que la vinculación de Adriano con la ciudad vendría condicionada por su buena o mala relación con su familia materna, en la que sin duda jugó un papel relevante la figura de Servianus. Esta relación pudo ser distante desde la juventud del Príncipe, cuando quedó a cargo de sus tutores, y no se puede entender sin incluir a Servianus en el grupo familiar.

\section{Referencias bibliográficas}

Alföldy, G.

(1969): Fasti Hispanienses. Senatorische Reichbeamte und Offiziere in den spanischen Provinzen des römischen Reiches von Augustus bis Diokletian, Wiesbaden.

(1977): Konsulat und Senatorenstand unter den Antoninen. Prosopographische Untersuchungen zur senatorischen Führungsschicht, Bonn.

(2014): "Hadrians Besuch in Tarraco (HA, H 12, 3-5)", [en] C. Bertrand-Dagenbach - F. Chausson (eds.), Historiae Augustae Colloquium Nanceiense. Atti dei Convegni sulla Historia Augusta XII (=Historiae Augustae Colloquia. Nova series 12), Bari, 11-29 (=G. Alföldy, "La visita de Adriano a Tarraco. HA, H 12, 3-5", [en] D. Gorostidi Pi (ed.), Géza Alföldy. Estudios tarraconenses, Tarragona 2017, 379-398).

Baratta, G. (2019): "Iustitia dicitur... erga parentes pietas (Cic. Part. Or., 78): il reflesso nella monetazione traianea", Minima Epigraphica et Papyrologica 24, 167-180 (https://doi. org/10.1400/271791).

Beaujeu, J. (1955): La religion romaine à l'apogée de l'Empire I. La politique religieuse des Antonins (96-192), Paris.

Bennett, J. (2001): Trajan. Optimus Princeps (=Roman Imperial Biographies), London-New York.

Bernard, A. - Bernard, E. (1960): Les inscriptions grecques et latines du Colosse de Memnon (=Institut Français d'Archéologie Orientale. Bibliothéque d'Étude 31), Paris.

Birley, A. R.

(2000): Hadrian, the Restless Emperor, London (https://doi.org/10.4324/9780203407240).

(2001):Marcus Aurelius. ABiography, NewYork(https://doi.org/10.4324/9780203137598).

(2004): "Los viajes de Adriano", [en] Cortés Copete - Muñiz Grijalvo (eds.), 2004, 57-69.

Blázquez Martínez, J. Ma (1982): "La Hispania de Hadriano", [en] En homenaje a Conchita Fernández-Chicarro, Madrid, 301-317.

Boatwright, M. Th. (1991): "The Imperial Women of the Early Second Century a.C.", The American Journal of Philology 112/4, 513-540 (https://doi.org/10.2307/294932).

Caballos Rufino, A.

(1978): “Colonia Claritas Iulia Ucubi”, Habis 9, 273-291 (http://dx.doi.org/10.12795/ Habis.1978.i09.16).

(1984): “P. Acilius Attianus”, Habis 15, 237-251 (http://dx.doi.org/10.12795/Habis.1984. i15.18).

(1986): "Los horóscopos de la Apotelesmática de Hefestión de Tebas y los senadores hispanorromanos", Memorias de Historia Antigua 7, 121-128.

(1990): Los senadores hispanorromanos y la romanización de Hispania (siglos I-III), (=Monografías del Departamento de Historia Antigua de la Universidad de Sevilla 5), Sevilla.

(2004): "Raíces hispanas de la familia imperial. De Trajano a Adriano", [en] Cortés Copete - Muñiz Grijalvo (eds.), 2004, 35-55. 
Canto de Gregorio, A. (2004): “Itálica sedes natalis de Adriano. 31 textos históricos y argumentos para una secular polémica", Athenaeum 92/2, 367-408.

Castillo García, C. (1982): "Los senadores béticos. Relaciones familiares y sociales", [en] Epigrafia e ordine senatorio II. Atti del Colloquio internazionale AIEGL su epigrafia e ordine senatorio (Roma 1981), (=Tituli 5), Roma, 465-519.

Chausson, F.

(2002): "Variétés généalogiques - I. Numa Pompilius ancêtre de Marc Aurèle", [en] G. Bonamente - F. Paschoud (cur.), Historiae Augustae Colloquium Perusinum. Atti dei Convegni sulla Historia Augusta VIII (Pérouse, 2000), (=Munera, Studi Storici sulla Tarda Antichità 18), Bari, 109-147.

(2007): "Variétés généalogiques - IV. Cohésion, collusions, collisions: une autre dynastie Antonine", [en] G. Bonamente - H. Brandt (cur.), Historiae Augustae Colloquium Bambergense, Atti dei Convegni sulla Historia Augusta X (Bamberg 2005), (=Munera, Studi Storici sulla Tarda Antichità 27), Bari, 123-163.

(2009a): "Amitiés, haines et testaments à Nîmes, en Bétique et à Rome: Cn. Domitius Afer, Sex. Curvius Tullus et leur descendance”, [en] Chausson (dir.), 2009, 191-216.

(2009b): “Les Annii Veri d'Vcubi”, [en] Chausson (dir.), 2009, 217-234.

(2013): "Le patriciat des Pedanii", Epigraphica 75, 167-186.

Chausson, F. (dir.), (2009): Occidents romains. Sénateurs, chevaliers, militaires, notables dans les provinces d'Occident (Espagnes, Gaules, Germanies, Bretagne), Paris.

Chaves Tristán, F. (2000): “Carteia”, [en] J. M. Abascal Palazón - P. P. Ripollès Alegre (eds.), Monedas Hispánicas (=Publicaciones del Gabinete de Antigüedades de la Real Academia de la Historia. Monedas y Medallas II.1.1), Madrid, 278-298.

Cortés Copete, J. M. - Muñiz Grijalvo, E. (eds.), (2004): Adriano Augusto, Sevilla.

Cruz Andreotti, G. (1994): "La visión de Gades en Estrabón. Elaboración de un paradigma geográfico", Dialogues d'Histoire Ancienne 20/1, 57-85 (https://doi.org/10.3406/ dha.1994.2145).

De la Rosa Cubo, C. (2005): "Pompeia Plotina, una emperatriz de la época de los Antoninos", [en] L. Hernández Guerra (ed.), La Hispania de los Antoninos (98-180). Actas del II Congreso Internacional de Historia Antigua (Valladolid 2004), (=Universidad de Valladolid. Centro Buendía 80), Valladolid, 203-212.

Delgado Delgado, J. A. (1993): "El culto a Júpiter, Juno y Minerva entre las élites béticas durante el alto Imperio Romano", Gerión 11, 337-363.

Des Boscs-Plateaux, F. (2005): Un parti hispanique à Rome? Ascension des èlites hispaniques et pouvoir politique d'Auguste à Hadrien (27 av. J.-C. - 138 ap. J.-C.), (=Bibliothèque de la Casa de Velázquez 32), Madrid.

Di Vita-Évrard, G.

(1987a): "Des Calvisii Rusones à Licinius Sura", Mélanges de l'École française de Rome. Antiquité 99/1, 281-338 (https://doi.org/10.3406/mefr.1987.1545).

(1987b): "Sur les charges africaines des frères Cn. Domitii Afri Titii Marcelli Curvii Lucanus et Tullus", [en] A. Mastino (cur.), L'Africa Romana. Atti del IV convegno di studio. Sassari 1986, Sassari, vol. II, 509-529.

(1989): "Le testament dit "de Dasumius": testateur et bénéficiaires", [en] C. Castillo (ed.), Epigrafia jurídica romana, Actas del Coloquio internacional A.I.E.G.L., Pamplona 1987, Pamplona, 159-174.

(2000): "La famiglia dell'imperatore: per delle nuove Memorie di Adriano", [en] Adriano. Architettura e progetto, Milano, 31-39.

Eck, W. 
(1970): Senatoren von Vespasian bis Hadrian (=Vestigia 13), München.

(1996): "I senatori e la loro provincia di origine. L'esempio della Baetica”, [en] W. Eck, Tra Epigrafia, Prosopografia e Archeologia. Scritti scelti, rielaborati ed aggiornati (=Vetera 10), Roma, 213-226.

Étienne, R.

(1965): "Les senateurs espagnols sous Trajan et Hadrien", [en] Les empereurs romains d'Espagne. Actes du Colloque international (Madrid-Italica, 31 mars-6 avril 1964), Paris, 55-85.

(1974): Le culte impérial dans la Péninsule Ibérique d'Auguste à Dioclétien (=Bibliothèque des Écoles françaises d'Athènes et de Rome 191), Paris.

Follet, S. (1968): "Hadrien en Égypte et en Judée", Revue de Philologie, de Littérature et d'Histoire Anciennes 42, 54-77.

García y Bellido, A. (1949): Esculturas romanas de España y Portugal, Madrid.

Garriguet Mata, J. A. (2001): Corpus signorum imperii Romani. Corpus de esculturas del imperio romano. España. Vol. 2.1. La imagen del poder imperial en Hispania. Tipos estatuarios, Murcia.

González Fernández, J. (1982): Inscripciones romanas de la provincia de Cádiz, Cádiz.

González-Conde Puente, $\mathrm{M}^{\mathrm{a}} \mathrm{P}$.

(2018a): "Hadriano e Hispania en las fuentes clásicas", Classica et Christiana 13, 17-32. (2018b): "Algunos temas de ideología imperial en las monedas de Trajano y Adriano", [en] A. Caballos Rufino (ed. cient.), De Trajano a Adriano. Roma matura, Roma mutans (=Editorial Universidad de Sevilla. Historia y Geografía 351), Sevilla, 129-148. (2019): Las provincias de Hispania en los años de Adriano, Zaragoza.

Halfmann, H. (1986): Itinera Principum. Geschichte und Typologie der Kaiserreisen im römischen Reich (=Heidelberger althistorische Beiträge und epigraphische Studien 2), Stuttgart.

Hidalgo de la Vega, M ${ }^{\mathrm{a}} \mathrm{J}$.

(2000): "Plotina, Sabina y las dos Faustinas: la función de las Augustas en la política imperial”, Studia Historica. Historia Antigua 18, 191-224.

(2002): "Los ciclos vitales de las princesas antoninas a la manera de un cursus honorum", [en] P. Pérez Cantó - M. Ortega López (eds.), Las edades de las mujeres, Madrid, 137-171. (2012): Las emperatrices romanas: sueños de púrpura y poder oculto (=Ediciones Universidad de Salamanca. Estudios Históricos y Geográficos 151), Salamanca.

Kienast, D. et alii (2917): Römische Kaisertabelle, Grundzüge einer römischen Kaiserchronologie, Darmstadt.

Mangas Manjarrés, J. (1989): "El «Hercules Gaditanus», dios heredero”, [en] Ma J. Hidalgo de la Vega (ed.), La Historia en el contexto de la Ciencias Humanas y Sociales. Homenaje a Marcelo Vigil Pascual (=Ediciones Universidad de Salamanca. Estudios Históricos y Geográficos 61), Salamanca, 55-60.

Mayer i Olivé, M. (2018): “Algunas reflexiones sobre la identidad de la madre de Trajano y las posibles razones de un silencio", Cahiers du Centre Gustave Glotz 29, 17-33.

McDermott, W. C. (1977): "Plotina Augusta and Nicomachus of Gerasa”, Historia: Zeitschrift für Alte Geschichte 26/2, 192-203.

Michelotto, P. G. (1987): "Intorno a Serviano cognato e vittima dell'Imperatore Adriano", [en] Studi di Antichità in memoria di Clementina Gatti (=Quaderni di Acme 9), Milano, 143-192.

Migliorati, G. (2003): Cassio Dione e l'impero romano da Nerva ad Antonino Pio. Alla luce dei nuevi documenti, Milano. 
Monterroso Checa, A. (2020): "La ubicación del santuario de Melqart en Gadir: aportación a los datos PNOA-LIDAR", Spal 30/1, 137-164 (https://doi.org/10.12795/spal.2021. i30.05).

Moreno Pulido, E. (2013): "Sumergidos en el Océano. Iconografía oceánica en el Extremo Occidente Antiguo", [en] A. J. Gullón Abao - A. Morgado García - J. J. Rodríguez Moreno (eds.), El mar en la historia y en la cultura (=Editorial UCA. Ceimar 5), Cádiz.

Navarro Caballero, M. (2017): Perfectissima femina. Femmes de l'élite dans l'Hispanie romaine (=Ausonius Éditions. Scripta Antiqua 101), Bordeaux, 2 vols.

Ojeda Nogales, D. (2017): Trajano y Adriano. Tipología estatuaria (=Editorial Universidad de Sevilla. Serie Historia y Geografía 199), Sevilla.

Oria Segura, M.

(1989): "Distribución del culto a Hércules en Hispania según los testimonios epigráficos", Habis 20, 263-273 (http://dx.doi.org/10.12795/Habis.1989.i20.19).

(1993): "El Hércules de Carteia en época imperial", Almoraima. Revista de Estudios Campogibraltareños 9, 163-174.

Padilla Monge, A. (2011): "Algunas cuestiones en torno a la élite de Carteia", Gerión 29/1, 239-263 (http://dx.doi.org/10.5209/rev_GERI.2011.v29.n1.39056).

Paratore, E. (1945): Plotina, Sabina e le due Faustine (=Istituto di Studi Romani. Quaderni di Studi Romani. Done di Roma Antica 2), Roma.

Pavón Torrejón, P. (2018): "Plotina Augusta: luces y sombras sobre una mujer de estado", Veleia 35, 21-39 (https://doi.org/10.1387/veleia.19441).

Perea Yébenes, S. (2001): Entre Occidente y Oriente. Temas de Historia Romana: aspectos religiosos (=Signifer. Graeco-Romanae Religionis Electa Collectio=GREC 4), Madrid.

Pfeiffer, S.

(2010): Der römische kaiser und das Land am Nil. Kaiserverehrung und Kaiserkult in Alexandria und Ägypten von Augustus bis Caracalla (30 v. Chr. - 217 n. Chr.), (=Historia, Einzelschriften 212), Stuttgart.

(2015): Griechische und lateinische Inschriften zum Ptolemäerreich und zur römischen Provinz Aegyptus. Einführungen und Quellentexte zur Ägyptologie (=Einführungen und Quellentexte zur Ägyptologie 9), Berlin.

Pflaum, H.-G. (1983): “Les Impératrices de l'époque des Antonins dans l'Histoire Auguste”, [en] Bonner Historia Augusta-Colloquium 1979-1981 (=Antiquitas 4), Bonn, 245-53.

Raepsaet-Charlier, M.-Th. (1987): Prosopographie des femmes de l'ordre sénatorial (Ier-IIe siècle), (=Fonds René Draguet 4), Louvain.

Rico, Ch. (1999): "Éléments pour une approche socio-économique de la production de matériaux de construction en terre cuite dans les provinces hispaniques", [en] M. Bendala - Ch. Rico - L. Roldán Gómez (eds.), El ladrillo y sus derivados en la época romana (=Monografías de Arquitectura romana 4), Madrid, 25-44.

Rodríguez Ferrer, A. (1988): "El Templo de Hércules-Melkart: un modelo de explotación económica y prestigio político", [en] G. Pereira Menaut (ed.), Actas del I Congreso Peninsular de Historia Antigua (Santiago de Compostela, 1-5 julio 1986), Santiago de Compostela, vol. 2, 101-110.

Rodríguez Oliva, P. (2011): "Notas sobre algunas antiguas investigaciones arqueológicas en Carteia”, Baetica 33, 111-175 (https://doi.org/10.24310/BAETICA.2011.v0i33.112).

Strack, P. (1931): Untersuchungen zur römischen Reichsprägung des zweiten Jahrhunderts, vol. I, Stuttgart.

Syme, R.

(1969): "Pliny the Procurator", Harvard Studies in Classical Philology 73, 201-236 
(=Roman Papers II, pp. 742-733), (http://dx.doi.org/10.2307/311156).

(1980): "Guard prefects of Trajan and Hadrian", The Journal of Roman Studies 70, 64-80 (http://dx.doi.org/10.2307/299556).

Temporini, H. (1978): Die Frauen am Hofe Traians. Ein Beitrag zur Stellung der Augustae im Prinzipat, Berlin-New York.

Temporini, H. - Vitzthum, G.

(1999): "Frauen im Bild der Domus Augusta unter Traian", [en] E. Schallmayer (ed.), Traian in Germanien, Traian im Reich (=Saalburgmuseum. Saalburg-Schriften 5), Bad Homburg, 45-53.

(2002): Die Kaiserinnen Roms. Von Livia bis Theodora, München.

Thomasson, B. E. (1984): Laterculi praesidum, Göteborg.

Woytek, B. (2010): Die Reichsprägung des Kaisers Traianus (98-117), (=Moneta Imperii Romani 14), Wien. 